\title{
Telomerization of Ethylene and Carbon Tetrachloride Initiated by Amines
}

\author{
Teruzo Asahara** and Jiro Hirano***
}

\begin{abstract}
Summary: The telomerization of ethylene and carbon tetrachloride is initiated by various amines in the absence of metallic salts in the stainless steel autoclave. In this reaction the initiating efficiency of amines depends upon their basicity and chemical structure. In general, strong bases are excellent initiators but the strength of the basicity of amines gives only a small effect on the composition of the telomer produced. The temperature of the reaction and the dielectric constant of the solvent have pronounced effects on this reaction process. And from these observation and the other experiments, the distinction between the present initiating system and the redox system of amine-metallic salt was discussed on the basis of the reaction mechanism involved.
\end{abstract}

\section{Introduction}

In our previous work ${ }^{11}$ the catalytic system of metallic salt and ethanolamine was systematically investigated as an initiator for the telomerization reaction of ethylene and carbon tetrachloride, and it was eventually found that this reaction could be initiated by alkanolamine alone in the stainless steel autoclave. From this observation, we assumed that the metallic salt was not the reagent necessary for the formation of a $\cdot \mathrm{CCl}_{3} \mathrm{ra}$ dical and that the radical could be produced by the reaction of carbon tetrachloride and amine under a catalytic influence of the metallic wall of the autoclave. Several investigators $^{2}$ reported that the interaction between carbon tetrachloride and amine was strongly catalyzed by metallic copper to give amine hydrochloride.

In the meantime, close correlation could not be found between the composition of the produced telomer and the amount of added copper salts in this telomerization. This fact would suggest that the copper complex $\mathrm{Cu}^{+}(\mathrm{Cl})$, produced from the oxidation of cuprous salt by carbon tetrachloride under the catalytic influence of alkanolamine, did not play

\footnotetext{
* Received December 7, 1964.

** Institute of Industrial Science, University of Tokyo, Azabu-Shinryudocho, Tokyo.

*** Nihon Oils and Fats Co., Chiyoda-Marunouchi, Tokyo.
}

such a significant role in the formation of telomers as described in Vofsi' paper ${ }^{3)}$, which reads as follows:

$$
\begin{aligned}
& \mathrm{Cu}^{+}+\mathrm{CCl}_{4} \longrightarrow \mathrm{Cu}^{+}(\mathrm{Cl})+\cdot \mathrm{CCl}_{3} \\
& \mathrm{Cu}^{+}(\mathrm{Cl})+\mathrm{CCl}_{3}\left(\mathrm{CH}_{2}\right)_{n} \cdot \\
& \longrightarrow \mathrm{CCl}_{3}\left(\mathrm{CH}_{2}\right)_{n} \mathrm{Cl}+\mathrm{Cu}^{+}
\end{aligned}
$$

In order to clarify some questions proposed by these observations, we have undertaken a detailed research on the telomerization of ethylene and carbon tetrachloride initiated by amines.

The objective of the present paper is to disclose what effects the basicity and the chemical structure of amines exerts upon the yield and the composition of the telomers produced, and then to discuss the differences between the catalytic activity of single amines and that of the amine-metallic salt system.

\section{Experimental}

Materials: All amines used were "guaranteed grade" products. Ethylene of a $99 \%$ purity was used. Carbon tetrachloride was purified as described in our previous paper ${ }^{11}$. "Chemically pure grade" tertiary butanol was used as an inert solvent in order to increase the molar ratio of ethylene to carbon tetrachloride in a reaction system.

Apparatus and Procedure: The autoclave of a $502 \mathrm{ml}$ capacity was made of SUS 27 
stainless steel and fitted with a magnetic stirrer.

A solution of a given amount of amine in $200 \mathrm{cc}$ of the mixture $(1: 1)$ of carbon tetrachloride and tertiary butanol was introduced into the autoclave. After the autoclave was closed and the air was displaced by ethylene, the autoclave is heated and the reaction was carried out for 4 hours at a given temperature. The reaction product was washed with acidic water to remove soluble amine hydrochloride and treated for the analysis of the produced telomer as described in our previous paper'.

\section{Results and Discussion}

Effect of the added metal

The metallic wall of the autoclave could not initiate the telomerization reaction of ethylene and carbon tetrachloride in the range of $40^{\circ} \mathrm{C}$ and $120^{\circ} \mathrm{C}$., if no amine was introduced into this system.

However, this reaction was broken out at $160^{\circ} \mathrm{C}$ or more through the thermal decomposition of carbon tetrachloride, but the conversion of carbon tetrachloride was small (lower than $10 \%$ ) and more than $50 \%$ of the produced telomers was dehydrochlorinated to $\alpha, \alpha, \omega$-trichloroalkene ${ }^{4)}$. The telomerization reaction also did not proceed in the presence of a catalytic amount ( 0.1 mole $\%)$ of cuprous, cupric, ferrous and ferric chloride up to the temperature of $100^{\circ} \mathrm{C}$.

The appreciable amount of a telomer mixture could be obtained only after many hours of reaction $(15 \sim 20$ hours $)$ in the presence of a large amount ( 5 mole $\%$ or more) of the metallic salts as described above under high temperatures of reaction $\left(100 \sim 145^{\circ} \mathrm{C}\right)^{5}$.

As metallic aluminum was used as a packing plate for the autoclave and it was reported $^{6)}$ that it reacts with carbon tetrachloride at $76.7^{\circ} \mathrm{C}$ to give hexachloroethane, the effect of granular metallic aluminum on the telomerization was examined in the absence or the presence of $n$-butyl amine. If the amine was absent, the telomerization reaction did not proceed even at $90^{\circ} \mathrm{C}$ for 4 hours. In the presence of the amine $\left(6 \times 10^{-2}\right.$ mole), the yield of the produced telomer $(95.0 \mathrm{~g})$ was not affected at all by the addition of granular aluminum $(0.1 \mathrm{~g} \cdot$ atom $)$ at $90^{\circ} \mathrm{C}$ for 4 hours under the ethylene pressure of $64 \mathrm{~kg} / \mathrm{cm}^{2}$. From these observations, it was concluded that metallic aluminum was inactive to carbon tetrachloride or the amine carbon tetrachloride system under the above described condition, as being shown also in Beichl's work ${ }^{7}$.

Effect of the basicity of amines

The interaction or, presumably, the complex formation between amine and carbon tetrachloride was reported to be dependent of the basicity of amines ${ }^{8}$. By assuming that the initiating radical $\cdot \mathrm{CCl}_{3}$ of the telomerization reaction is produced by the thermal disruption of the intermediate compound of amine and carbon tetrachloride and that this intermediate formation is related to the basicity of amines, a close relation is expected between the basicity of amine and the yield of the telomer. In fact, Table 1 shows that

Table 1 Influence of the basicity of amine on the yield of telomer*

\begin{tabular}{|c|c|c|}
\hline Amine & $\begin{array}{c}{ }_{\mathrm{p}} \mathrm{K}_{\mathrm{B}} \\
\text { value }\end{array}$ & $\begin{array}{c}\text { Yield of } \\
\text { Telomer, } \\
\mathrm{g} / 100 \mathrm{cc} \text { of } \mathrm{CCl}_{4}\end{array}$ \\
\hline$n$-butyl amine & 3.39 & 18.1 \\
\hline$n$-hexyl amine & 3.36 & 12.8 \\
\hline$n$-dodecyl amine & & 15.1 \\
\hline$d i$-ethyl amine & 3.01 & Trace \\
\hline$d i$-propyl amine & 3.10 & Trace \\
\hline$d i$-butyl amine & 2.79 & 33.5 \\
\hline Ethylene diamine & 4.07 & 5.0 \\
\hline Hexamethylene diamine & & 0 \\
\hline Pyrrolidine & 2.73 & 16.6 \\
\hline Piperidine & 2.80 & 24.5 \\
\hline Cyclohexyl amine & 3.31 & 20.0 \\
\hline Morpholine & 5.64 & 15.9 \\
\hline Pyrrolidinone & & Trace \\
\hline Benzyl amine & 4.63 & 1.8 \\
\hline Pyridine & 8.85 & 0 \\
\hline Aniline & 9.42 & 0 \\
\hline$N, N$-dimethyl aniline & 1 & 0 \\
\hline Pyrrole & 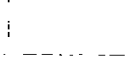 & 0 \\
\hline Monoethanol amine & 4.56 & 194.2 \\
\hline Diethanol amine & 5.05 & 92.9 \\
\hline Triethanol amine & 6.18 & 117.9 \\
\hline \multicolumn{3}{|l|}{ * Concentration of amine: } \\
\hline Reaction press. : & \multicolumn{2}{|c|}{$50 \sim 57 \mathrm{~kg} / \mathrm{cm}^{2}$} \\
\hline Reaction temp. & \multicolumn{2}{|c|}{$90^{\circ} \mathrm{C}$} \\
\hline Reaction time & \multicolumn{2}{|l|}{4 hours } \\
\hline Volume Ratio & \multicolumn{2}{|l|}{0.4} \\
\hline
\end{tabular}

Bulletin of The Japan Petroleum Institute 
such a close relation exists in the telomerization initiated by amines. As shown in Table 1 , aromatic amines have only small or completely no effect on this reaction because of their low basicity, and alicyclic amines have an excellent initiating activity owing to their structural saturation. Alkanolamines were distinguished initiators in spite of their relatively low basicity. Their excellent initiating activity results presumably from their hydroxyl group, for it was said that this group has the ability of the co-ordination in a non-aqueous medium ${ }^{9}$.

On the contrary, the composition of the produced telomer was merely affected by the basicity of amines, as shown in Fig. 1 .

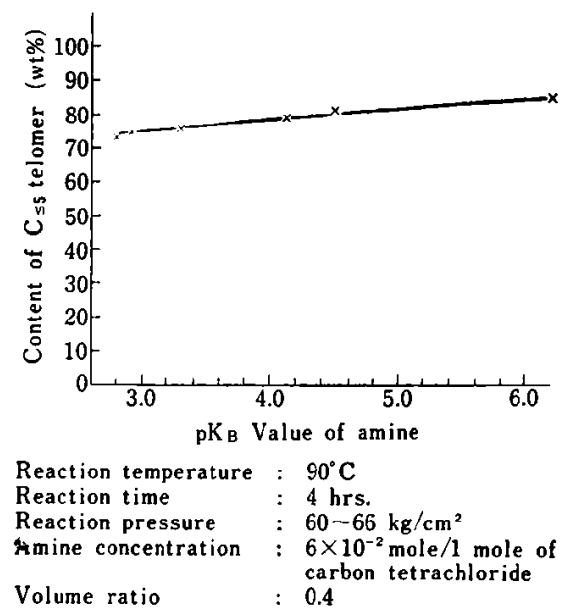

Fig. 1 Influence of ${ }_{p} K_{B}$ value of amine on the content of telomer

Effect of the chemical structure of amines The effect of the chemical structure of amines on the telomerization was shown in Figs. 2 and 3.

Figure 2 shows that the steric factor of amines gives a more pronounced effect on this reaction than their basicity and that primary amines have an unusually larger initiating activity than secondary and tertiary amines. Moreover, Figure 3 shows that branched amines are inferior to the normal ones in their initiating ability. The amines, which have the same number e.g., 6 of the carbon atoms, have the increasing catalytic activities in the following order:

$$
\begin{aligned}
& \text { dipropyl }(0 \%, 3.10) \\
& \quad<\text { triethyl }(1.7 \%, 3.07) \\
& <n \text {-hexyl }(5.1 \%, 3.36)
\end{aligned}
$$

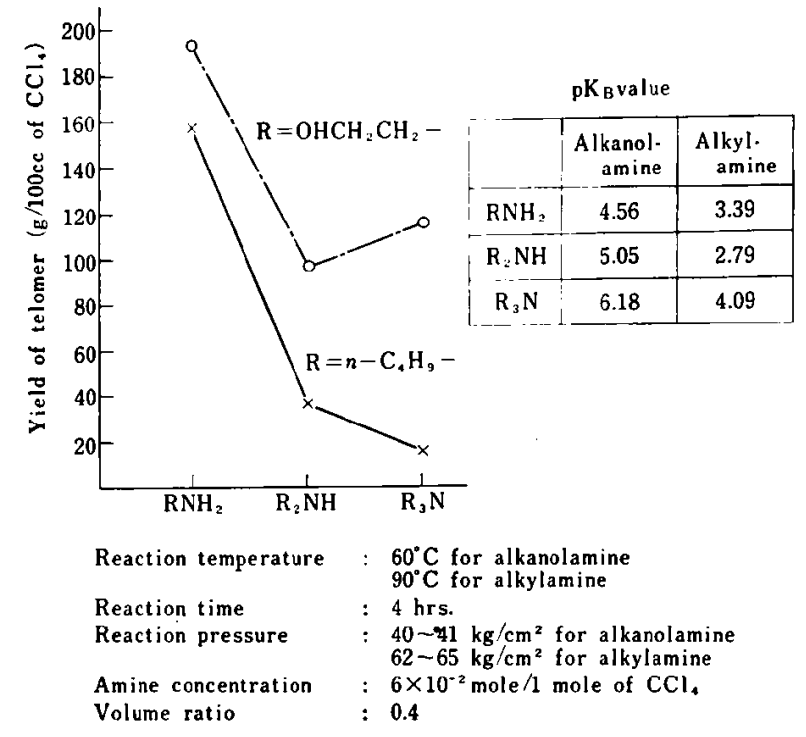

Fig. 2 Influence of chemical structure on the yield of telomer

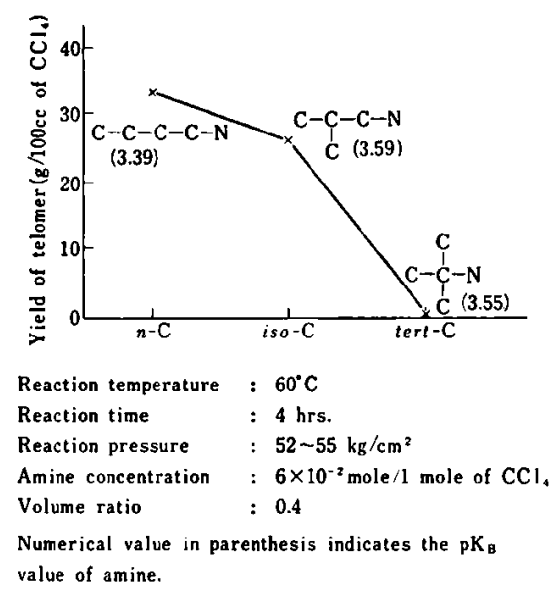

Fig. 3 Influence of chemical structure on the yield of telomer

The first numerical values in parenthes indicates the percent conversion of carbon tetrachloride in the telomerization at $90^{\circ} \mathrm{C}$ for 4 hours at $52 \mathrm{~kg} / \mathrm{cm}^{2}$ of ethylene pressure, and the second figures show the ${ }_{\mathrm{p}} \mathrm{K}_{\mathrm{B}}$ value of the amines. All these results suggest that the pronounced steric effect of amines should originate from the co-ordination of the amine with a bulky molecule of carbon tetrachloride.

Effect of the concentration of amine

The yield of the telomer is depended upon the amount of the added amine, as shown in Fig. 4. There is observed a maximum initiating efficiency of amines at their optimum concentration, and at higher concentrations the efficiency decreases of the amount of amine. This behavior was also observed in 


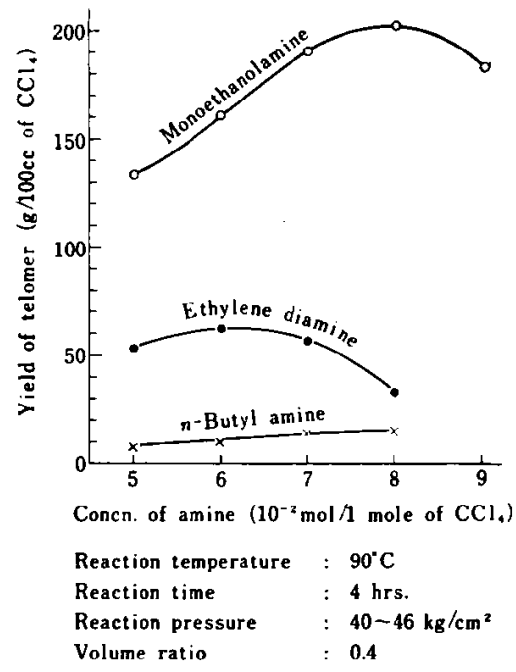

Fig. 4 Influence of amine concentration on the yield of telomer

the initiating system of the triethanolamine copper salt", and should be ascribed to the increasing probability of the recombination of the $\cdot \mathrm{CCl}_{3}$ radical and the resulting decrease of the initiating efficiency, with the increase of the amine concentration.

\section{Effect of the reaction temperature}

The influence of the reaction temperature on the yield of telomers is shown in Fig. 5, which indicates that alkanolamine has its maximum catalytic activity even at the lower temperature of reaction and loses its activity rather abruptly with the increase of the temperature. On the other hand, the initiating activity of aliphatic and alicyclic amines increases suddenly at their optimum temperature of reaction.

The basicity of amine decreases in a re- gular manner with the increase of temperature ${ }^{10)}$.

Therefore, it is anticipated that the coordination bond between amine and carbon tetrachloride becomes more unstable with the higher reaction temperature. On the other hand, Russian investigators ${ }^{112}$ reported that the velocity of the telomer formation coincided with that of the thermal decomposition of azobisisobutyronitrile used as an initiator.

It would seem on the basis of these results that the steep rise in the yield of telomers, as shown in Fig. 5, results from the sudden thermal decomposition of the intermediate compound of amine and carbon tetrachloride, followed by the rapid formation of the initiating radical $\cdot \mathrm{CCl}_{\mathrm{a}}$ through this disruption of the said intermediate compound.

In Fig. 5, it may be noted that the strong bases, for example, piperidine $\left({ }_{p} K_{B}=2.80\right)$, have the higher temperature of a steep rise in the telomer formation than the weak bases such as $n$-butyl $\left({ }_{\mathrm{p}} \mathrm{K}_{\mathrm{B}}=3.39\right)$ and $n$-hexyl $\left({ }_{\mathrm{P}} \mathrm{K}_{\mathrm{B}}=3.36\right)$ amines. This behavior suggests that the strong base requires more energy for the disruption of the intermediate compound of amine and carbon tetrachloride than the weak base.

\section{Effect of added solvent}

In the previous section, we described the pronounced influence of the basicity of amine on the yield of telomers. The basicity of amines varies with the medium in which they exist. Moreover, solvents should reveal their inhibitory action and transferring acti-
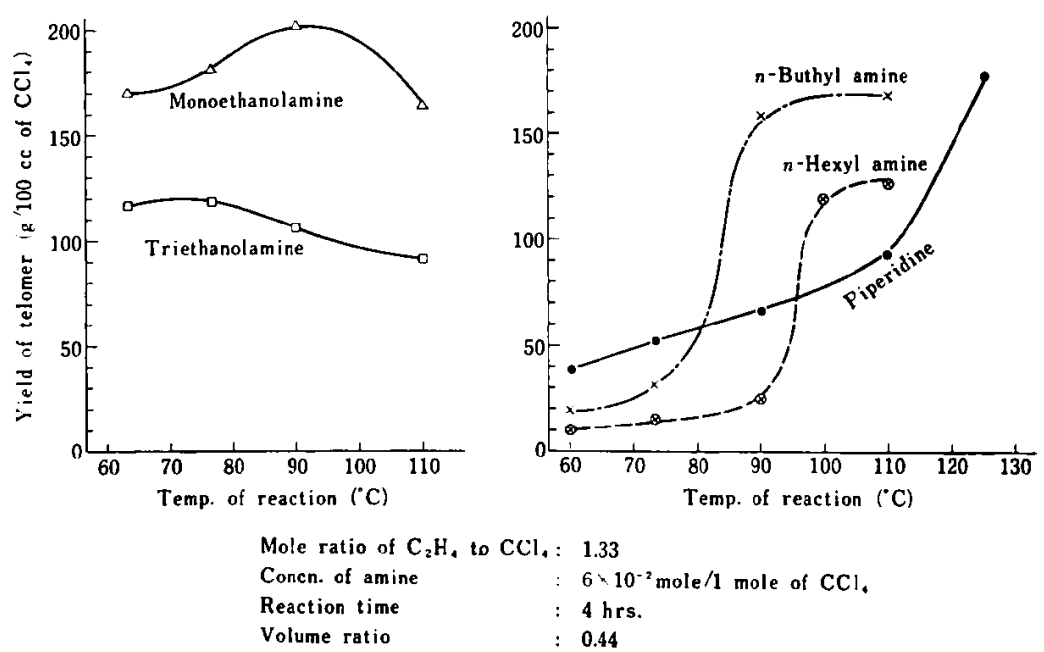

Fig. 5 Influence of reaction temperature on the yield of telomer 
Table 2 Influence of dielectric constant of aprotic solvent on the yield and composition of telomer*

\begin{tabular}{|c|c|c|c|c|c|}
\hline \multirow{2}{*}{ Solvent } & \multirow{2}{*}{$\begin{array}{c}\text { Dielectric } \\
\text { const. of } \\
\text { solvent }\end{array}$} & \multicolumn{2}{|c|}{$\begin{array}{l}\text { Yield of telomer, } \\
\mathrm{g} / 100 \mathrm{ce} \text { of } \mathrm{CCl}_{4}\end{array}$} & \multicolumn{2}{|c|}{$\begin{array}{c}\text { Content of } \mathrm{C}_{\leq b} \text { telomer, } \\
\text { wt. } \%\end{array}$} \\
\hline & & $\left|\begin{array}{c}\text { Monoethanol } \\
\text { amine }\end{array}\right|$ & $\begin{array}{l}\text { n-Butyl } \\
\text { amine }\end{array}$ & $\left|\begin{array}{c}\text { Monoethanol } \\
\text { amine }\end{array}\right|$ & $\begin{array}{l}n \text {-Butyl } \\
\text { amine }\end{array}$ \\
\hline$n$-heptane & 1.92 & 5.5 & 29.0 & - & 70.0 \\
\hline Cyclohexane & 2.02 & 13.2 & 36.0 & 88.6 & 85.4 \\
\hline 1, 4-dioxane & 2.04 & 68.1 & 66.0 & 75.9 & 88.7 \\
\hline Carbon tetrachloride & 2.22 & 22.5 & 55.5 & 80.9 & 91.1 \\
\hline Tetrahydrofuran & 7.3 & 28.7 & 81.0 & 68.8 & 82.0 \\
\hline Acetone & 20.7 & 2.0 & 8.9 & - & - \\
\hline Dimethylformamide & 26.6 & 73.5 & 26.0 & 88.3 & 89.9 \\
\hline Benzene & 2.27 & 12.0 & 9.5 & - & - \\
\hline Toluene & 2.38 & 6.0 & 9.5 & - & - \\
\hline Chlorobenzene & 5.62 & 5.0 & 4.0 & 一 & - \\
\hline Nitrobenzene & 34.8 & 0 & 6.5 & - & - \\
\hline
\end{tabular}

* Amount of solvent added: $100 \mathrm{cc} / 100 \mathrm{ce}$ of $\mathrm{CCl}_{4}$

Amine concentration : $6 \times 10^{-2} \mathrm{~mole} / 1$ mole of $\mathrm{CCl}_{4}$

Reaction press. $\quad: 60 \sim 69.5 \mathrm{~kg} / \mathrm{cm}^{2}$

Reaction temp. $\quad: 90^{\circ} \mathrm{C}$

Reaction time : 4 hours

Volume ratio $\quad: 0.4$

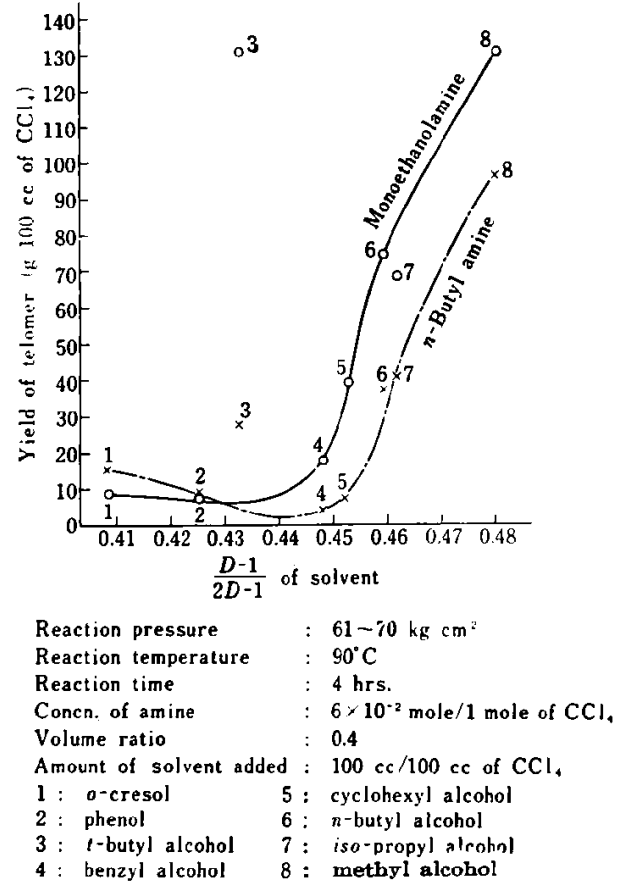

Fig. 6 Influence of dielectric constant of hydroxylic solvent on the yield of telomer

vity. Therefore, the effect of the solvent on the yield of telomers is interesting for investigation. The results were shown in Fig. 6 and Table 2. In these experiments, $100 \mathrm{cc}$ of solvents was added to $100 \mathrm{cc}$ of carbon tetrachloride. Fig. 6 shows the dielectric constant of the solvents, when hydroxylic solvents were used. Generally, the higher dielectric constants the solvents have, the more yields of telomers is obtained.

When aprotic solvents were used, such a regular relation was not found, as shown in Table 2.

Tertiary butanol is an excellent solvent for this telomerization, probably because it has no active hydrogen atom at the $\alpha$-position to the hydroxylic group. Aromatic solvents are generally inadequate for this reaction. Bagdasarian ${ }^{12}$ explained the inhibitive action of the aromatic solvent in the polymerization of vinyl monomers through the formation of the following stable intermediate radical:

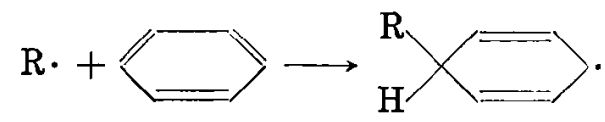

Distinction between the single amine catalyst was discussed and the redox system of amine $\sim$ metallic salt.

In the telomerization of ethylene and carbon tetrachloride, we could not find any essential differences between the single amine catalyst and the redox system of amine $\sim$ metallic salt, as reported in Figs. 1 and 3 of our previous paper $^{12}$. The copper complex $\mathrm{Cu}^{+}(\mathrm{Cl})$ in equations (1) and (2) do not reveal its inherent activity of Cl-ligand transfer in the formation of telomers. 
Asscher $^{3}$ proposed an explanation for such an activity in the addition of chloroform to octane-1 and proposed the following scheme:

$$
\begin{aligned}
& \mathrm{Cu}^{+}+\mathrm{CHCl}_{3} \\
& \stackrel{\mathrm{Cu}^{+}(\mathrm{Cl})+\cdot \mathrm{CHCl}_{2}}{\longrightarrow \mathrm{CHCl}_{2}}+\mathrm{CH}_{2}=\mathrm{CH}-\mathrm{R} \\
& \stackrel{\longrightarrow}{\longrightarrow} \mathrm{CHCl}_{2}-\mathrm{CH}_{2}-\dot{\mathrm{C}} \mathrm{H}-\mathrm{R} \\
& \stackrel{\mathrm{CHCl}}{2}-\mathrm{CH}_{2}-\dot{\mathrm{C}} \mathrm{H}-\mathrm{R}+\mathrm{Cu}^{+}(\mathrm{Cl}) \\
& \stackrel{\mathrm{CHCl}}{2}-\mathrm{CH}_{2}-\mathrm{CHCl}-\mathrm{R}+\mathrm{Cu}^{+}
\end{aligned}
$$

If ethylene acts as olefine in this reaction, the telomer produced should be $\alpha, \alpha, \omega$-trichloroalkane.

On the contrary, the telomer of $\alpha, \alpha, \alpha-$ trichloroalkane was obtained in the telomerization initiated by peroxide through the following Kharash's mechanism ${ }^{13}$ :

$$
\begin{aligned}
& \mathrm{P}-\mathrm{P} \longrightarrow 2 \mathrm{P} \cdot \\
& \mathrm{P} \cdot+\mathrm{CHCl}_{3} \longrightarrow \mathrm{PH}+\cdot \mathrm{CCl}_{3} \\
& \stackrel{\mathrm{CCl}_{3}+n \mathrm{CH}_{2}=\mathrm{CH}_{2}}{\longrightarrow} \mathrm{CCl}_{3}\left(\mathrm{CH}_{2} \mathrm{CH}_{2}\right)_{n} \cdot \\
& \stackrel{\mathrm{CCl}_{3}\left(\mathrm{CH}_{2} \mathrm{CH}_{2}\right)_{n} \cdot+\mathrm{CHCl}_{3}}{\longrightarrow} \mathrm{CCl}_{3}\left(\mathrm{CH}_{2} \mathrm{CH}_{2}\right)_{n} \mathrm{H}+\cdot \mathrm{CCl}_{3}
\end{aligned}
$$

In order to make clear the reaction mechanism in the present catalysis system, we carried out the telomerization of ethylene and chloroform, using the single amine or the redox system of amine + metallic salt as the initiator, under the following condition: $6 \times 10^{-2}$ mole of $n$-butyl amine was used as initiator, and $5 \times 10^{-8}$ mole of $\mathrm{CuCl}$ was admixed to the above amine in case of a redox catalyst. Telomerization was carried out at $90^{\circ} \mathrm{C}$ for 4 hours under the ethylene pressure of $83 \sim 70 \mathrm{~kg} / \mathrm{cm}^{2}$. From $200 \mathrm{cc}$ of $\mathrm{CHCl}_{3}$, $35 \mathrm{~g}$ of the telomer (I) was obtained by the redox catalyst, and $59 \mathrm{~g}$ (II) was obtained by the single amine. These telomers were gaschromatographed at $190^{\circ} \mathrm{C}$ in a $3-\mathrm{m}$ column using silicone oil as the stationary phase. The result was that the telomer (I) showed only a single main peak at the retention time of $2.70 \mathrm{~min}$. and the telomer (II) showed three peaks at the retention times of 1.85 , 2.95 and $5.21 \mathrm{~min}$. Infrared spectra of these telomers showed that the telomer (II) had two characteristic absorptions of the $\mathrm{CCl}_{3}$ group at 775 and $695 \mathrm{~cm}^{-1}$ and that the telomer (I) showed a strong absorption at $770 \mathrm{~cm}^{-1}$ and a medium absorption at 642 $\mathrm{cm}^{-1}$. Absorption at $642 \mathrm{~cm}^{-1}$ may be assigned to the vibration of the terminal $\mathrm{C}-\mathrm{Cl}$ bond. The telomer (II) has no absorption bands between 690 and $600 \mathrm{~cm}^{-1}$.

From these observations, it is concluded that the telomer (I) is $\alpha, \alpha, \omega$-trichloroalkane and the telomer (II) is $\alpha, \alpha, \alpha$-trichloroalkane. Therefore, in a redox system, the metallic salt is participated in this reaction at the following two stages: (a) Cl-abstraction from chloroform and (b) Cl-ligand transfer to the growing radical. But, in case of a single amine catalyst, such a behavior was not observed and the $\mathrm{H}$-abstraction from chloroform proceeds as normally as in the peroxide initiating system, presumably through the transient hydrogen-bonding state between chloroform and amine. In other words, metallic salt do not play any role in the single amine catalyst system.

\section{Acknowledgement}

We wish to express our cordial thanks to Dr. Y. Takagi for his valuable discussions and to Mr. H. Nakano for his assistance in performing the experiments.

\section{References}

1) Asahara, T., Hirano, J., Bull. Japan Petrol. Inst., 6, 65 (1964).

2) Collins, R. H., Chem. \& Ind., June 1, 704 (1957); Cromwell, N. H., Foster, P. W., Wheeler, M. M., ibid., Feb. 14, 228 (1959).

3) Asscher, M., Vofsi, D., Chem. \& Ind., Feb. 3, 209 (1962).

4) Asahara, T., Takagi, Y., Hirano, J., Nishizaki, S., Kase, M., 16th Anual Meeting of Japan Chem. Soc., Apr. 2 (1963).

5) Badische Anilin-\& Soda-Fabrik Akt., German Pat. 1,027,649, Oct. 2 (1958).

6) Asaoka, T., J. Soc. Org. Synthetic Chem., Japan, 22, 816 (1964).

7) Beichl, G. J., Colwell, J. E., Miller, J. G., Chem. \& Ind., Feb. 20, 203 (1960).

8) Snarpe, A.N., Walker, S., J.Chem. Soc., 2974 (1961).

9) Flannery, R. J., Grieb, B. K. M.W., Trivich, D., J. Am. Chem. Soc., 77, 2996 (1955).

10) Hall, N. F., Sprinkle, M. R., J. Am. Chem. Soc., 54, 3469 (1932).

11) Freidlina, R. Kh., Vasil'eva, E. I., Khim. Nauk $i$ Prom., 2, 2 (1957).

12) Bagdasarian, KH. S., J. Polymer Sci., 52, 31 (1961).

13) Kharash, M.S., Jensen, E.V., Urry, W. H., J. Am. Chem. Soc., 69, 1100 (1947); Harmon, J., Ford, T. A., Hanford, W. E., Joyce, R. M., ibid., 72, 2213 (1950). 